\section{Do you see patients with dry mouth?}

Dry mouth can affect as many as one in four patients and can have a significant impact on oral health, as well as physical and psychological wellbeing.

Oralieve products have been specifically designed and tested with dry mouth sufferers to help supplement the natural protective enzyme system in saliva and provide effective, lasting relief for dry mouth.

Free from strong flavours, alcohol and SLS, Oralieve products help maintain oral health and improve comfort for those patients who may be suffering with dry mouth because of diabetes, polypharmacy, Sjögren's syndrome, cancer treatment, depression or dementia. The entire range is available over the counter through Oralieve's online store, Amazon and 500+ Lloyd's Pharmacies, and Oralieve Moisturising Mouth Gel and Moisturising Mouth Spray are also available on prescription from GPs.

To request patient samples and literature, access online CPD modules and further information, visit www.oralieve.co.uk.

Email: hello@oralieve.co.uk. Phone: 01582439122.

\section{Looking ahead}

JBT dental study tours understand that it's difficult for people to consider travel at this time. However, looking ahead and remembering that this unsettling time will pass is also greatly reassuring. It can be a great boost to have something to look forward to. Planning holidays, study trips and continuing professional development are still important, and possible, and they help us to maintain balance.

JBT have many wonderful travel experiences to look forward to once this uncertain period has passed. These include dental study tours, with opportunities to discover new destinations and cultures as well as earning invaluable CPD points. JBT dental study tours are led by specialists in their fields and include professional programmes offering real insight into dentistry through wide ranging visits, talks and opportunities to meet with your counterparts in other countries.

JBT's forthcoming dental tours include Iceland, China, Ecuador and the beautiful Galapagos Islands. Visit www.jonbainestours.com/ tours for more information on all upcoming tours.

To help you plan at this time without any additional financial stress, JBT is offering fully refundable deposits on all 2021 tours. If you book

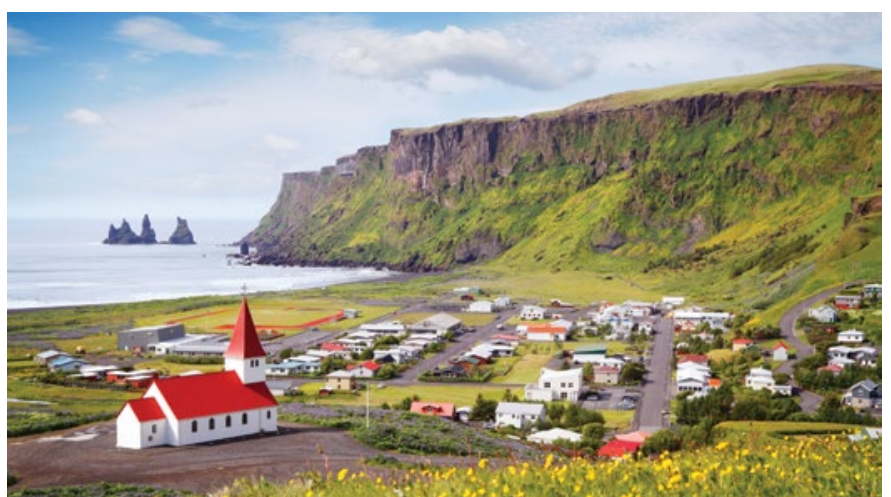

The most southerly town in Iceland, Vik

on any tour departing in 2021 by 30 June 2020, it will offer a fully refundable deposit until the end of July $2020^{*}$.

Contact Jon Baines Tours on +44 (0)20 72239485 or info@ jonbainestours.co.uk.

*Simply book on any 2021 tour as usual and the special terms will automatically apply. You will be contacted at the end of July to confirm your place under the usual booking terms.

\title{
You're invited to an online congress
}

Extraordinary situations require extraordinary solutions. In response to cancelled congresses and symposia Geistlich Pharma invites participants to the first online congress on 20 May 2020. Internationally renowned experts and speakers in dentistry have quickly and unbureaucratically pledged their commitment.

The online congress of the regeneration specialist Geistlich Pharma is freely accessible and open to an international audience. It is held over two time blocks and thus enables interested parties from all over the world to participate. Geistlich is expecting around 10,000 registered participants.

Dentistry is very much affected by the extraordinary situation caused by the coronavirus. Geistlich takes this fact into account. On the one hand, the congress topic refers to the daily routine of dental practice and treatments that do not follow the standard course.
On the other hand, the congress is intended to provide a forum to discuss issues in the context of the corona crisis.

Geistlich COO Dr Matthias Dunkel commented on the programme: 'Our goal is to create real added value for the participants with current and relevant topics.' A total of 12 different presentations are on the programme, plus four 'springboard' presentations for new, as yet unknown talents. The first 12 speakers include internationally renowned names such as Prof Istvan Urban, Dr Isabella Rocchietta, Prof Daniel Buser and Prof Christoph Hämmerle. Four time slots are reserved exclusively for younger and ambitious speakers. Dr Dunkel said: 'We are delighted to be able to help talented people make the leap into the international congress world'.

Further information: http://www.congress.geistlich-pharma.com. 